\title{
CROSS: A Multicriteria Group-Decision-Making Model for Evaluating and Prioritizing Advanced-Technology Projects at NASA
}

\author{
Madjid Tavana \\ Management Department, La Salle University, Philadelphia, Pennsylvania 19141-1199 \\ tavana@lasalle.edu
}

This paper was refereed.

\begin{abstract}
Evaluating and prioritizing advanced-technology projects is a particularly difficult task for the staff at the Kennedy Space Center (KSC) shuttle project engineering office. Because the evaluation process is complex and unstructured, decision makers (DMs) must consider vast amounts of diverse information concerning safety, systems engineering, cost savings, process enhancement, reliability, and implementation. Intuitive methods developed in the past have helped them to use large volumes of information in evaluating projects. However, these intuitive methods do not provide a structured framework for systematic evaluation. CROSS (consensus-ranking organizational-support system) is a multicriteria group-decision-making model that I implemented successfully at KSC to capture the DMs' beliefs through sequential, rational, and analytical processes. CROSS uses the analytic hierarchy process (AHP), subjective probabilities, the entropy concept, and the maximize-agreement heuristic (MAH) to enhance the DMs' intuition in evaluating sets of projects.

(Government: programs. Decision analysis: multiple criteria.)
\end{abstract}

$\mathrm{T}$ he rapid development of technology over the last few decades and the increased awareness of its effects on society have focused critical attention on government agencies that support technology development. The public is concerned with the governance of these agencies and with obtaining the maximum return from public investment in advanced technology. Public pressure has forced Congress to mandate the National Aeronautic and Space Administration (NASA) to be more accountable in its evaluation of advanced-technology projects. The demand for accountability, the pressure to cut costs, and the increasing number of projects have made evaluating projects extremely difficult.

Over the last several decades, analysts have developed a philosophy and a body of intuitive and analytical models to help decision makers (DMs) to evaluate and select projects. However, the intuitive models do not offer a structured framework for evaluating projects systematically, while the analytical models are not intended to capture intuitive preferences. The literature on project selection contains hundreds of models, including scoring methods, economic methods, portfolio methods, and decision analysis.

Scoring methods use algebraic formulas to produce a score for each project (Lockett et al. 1984, Melachrinoudis and Rice 1991, Moore and Baker 1969). Economic methods use financial models to calculate the monetary payoff of each project under consideration (Graves and Ringuest 1991, Mehrez 1988). Portfolio methods evaluate the entire set 
of projects to identify the most attractive subset (Lootsma et al. 1990, Vepsalainen and Lauro 1988). A specific form of portfolio analysis, cluster analysis, groups projects according to their support of the strategic positioning of the firm (Mathieu and Gibson 1993). Decision-analysis models compare various projects according to their expected value (Hazelrigg and Huband 1985, Thomas 1985). Finally, simulation, a special form of decision analysis, uses random numbers to generate a large number of problems. For each problem, the simulation develops many variables and constraints. Analysts then use the model to compare various projects and pick the best outcome (Mandakovic and Souder 1985).

Analysts have used most of these models to evaluate research and development projects (Coffin and Taylor 1996, Fahrni 1990, Taylor et al. 1982, Weber et al. 1990), information systems projects (Muralidhar et al. 1990, Santhanam and Kyparisis 1995, Santhanam et al. 1989, Schniederjans and Santhanam 1993), and capital budgeting projects (Graves and Ringuest 1991, Mehrez 1988). Recently, researchers working on project evaluation and selection have focused on multicriteria decision models. These models have made definitive contributions to project evaluation but do not integrate the intuitive preferences of multiple DMs into a structured and analytical framework. The consensusranking organizational-support system (CROSS) is a multicriteria group-decision-making model that captures the DMs' beliefs and enhances their intuition. CROSS employs a series of intuitive and analytical methods, such as the analytic hierarchy process (AHP), subjective probabilities, the entropy concept, and the maximize-agreement heuristic (MAH), to enhance the $\mathrm{DMs}^{\prime}$ intuition in evaluating a set of projects.

Before I implemented CROSS, the shuttle project engineering office staff used a simple, intuitive approach to assess advanced-technology projects initiated by a contractor or a division within the Kennedy Space Center (KSC). Project evaluation is the primary responsibility of the ground-system working committee, which has 15 members (five voting and 10 advisory). I refer to the five voting members as the DMs.
Once a year, contractors and divisions within KSC submit approximately 30 to 50 proposals for evaluation and possible funding. The committee considers the importance of each project relative to the longevity of the space-shuttle program. Each of the 15 committee members represents a specific department at the KSC. The committee holds weekly meetings to discuss ground-operations issues related to launches. The proposed advanced-technology projects are independent requests for engineering changes to the space shuttle-program. Contractors and KSC divisions submit proposals for dependent, nonadditive, or ongoing projects for separate evaluation at KSC's headquarters. After discussing each project, the five DMs each assign a numerical score between 1 and 10 to reflect their assessments of the project. They average these scores to produce an overall score. Based on the overall scores, the committee sorts the projects into three categories: superior projects that should definitely be funded, borderline projects that merit consideration for funding, and inferior projects that do not qualify. Typically, the superior projects consume a large part of the available budget. The committee reviews the borderline projects a second time. It then selects the set of projects that fits within the remaining budget and seems to best meet the $\mathrm{KSC}^{\prime} \mathrm{s}$ objectives. The KSC management then reviews the committee's funding choices for final approval.

Because the project-valuation process at KSC is quite intuitive, management expressed concern about its subjectivity and the potential for inconsistency. It wanted to replace the intuitive process with a more comprehensive and structured framework. I received a fellowship grant to develop and implement CROSS at the KSC.

\section{The Procedure}

CROSS guides the DMs through a systematic evaluation of the projects and uses the DMs' judgments to construct an overall composite score called the project success factor. CROSS has three phases: an interaction phase, an integration phase, and an interpretation phase (Figure 1). Each phase consists of several steps. The evaluation process begins with an initial interaction of the DMs. DMs are permanent members of the 


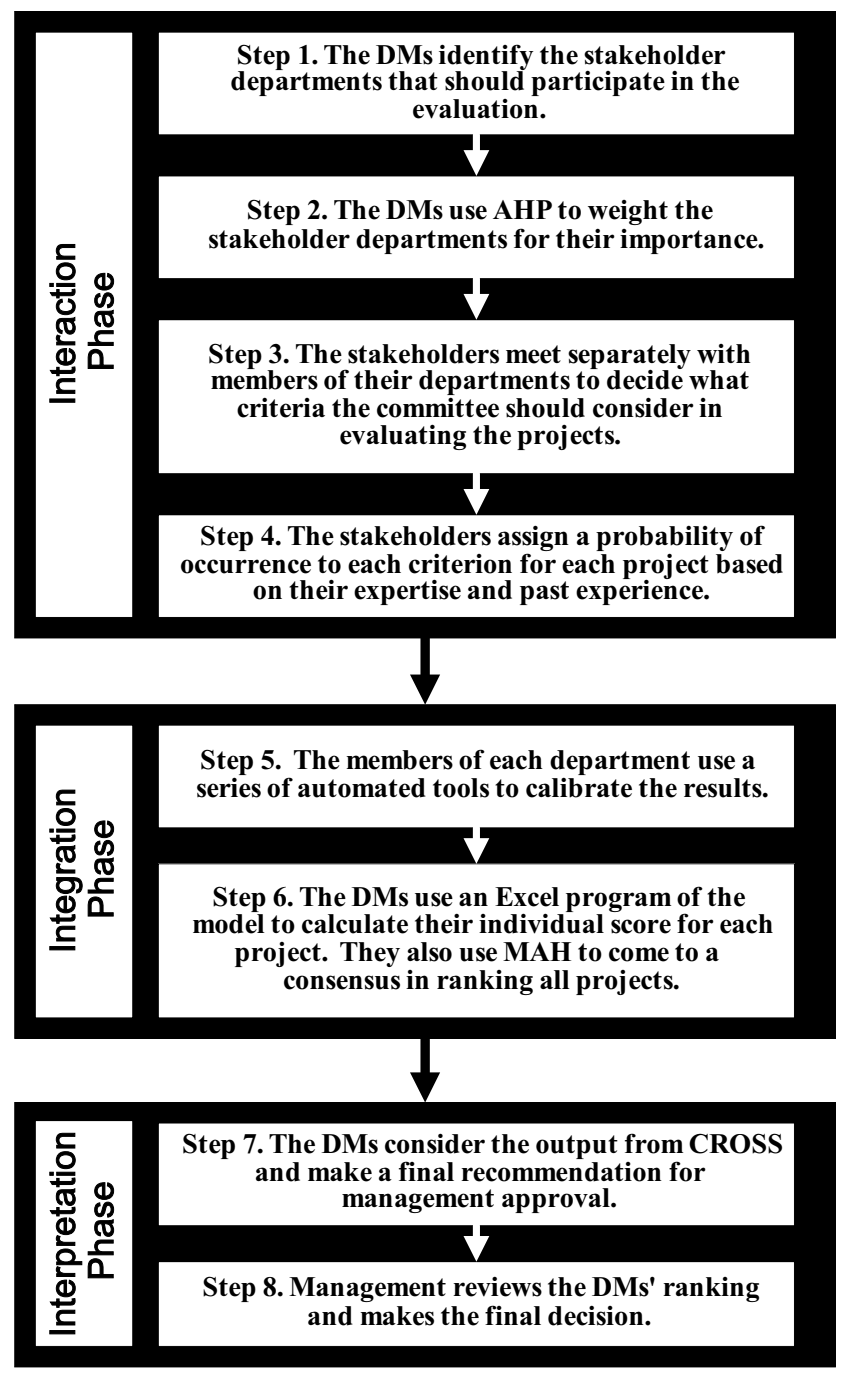

Figure 1: CROSS has three phases: an interaction phase, an integration phase, and an interpretation phase. Each phase consists of several steps.

ground-system working group committee appointed by KSC management to evaluate projects. After a preliminary review of the project proposals, the DMs identify the stakeholder departments that should participate in the evaluation (step 1). Stakeholder departments are responsible for the implementation of the selected projects. After KSC management approves the list of representatives designated by the stakeholder departments, the five DMs who are permanent members of the committee are joined by 10 nonvoting representatives from the stakeholder departments.
The DMs use AHP in step 2 to weight the stakeholder departments for their importance. Next, the committee gives the stakeholder members detailed and comprehensive information about the proposed projects. In step 3, the stakeholders meet separately with members of their departments to decide what criteria the committee should consider in evaluating the projects. They also use AHP to weight these criteria for their importance. Then, the members of each stakeholder department meet in several brainstorming sessions to assign a probability of occurrence to each criterion for each project based on their expertise and past experience (step 4). After gathering this information, the members of each department use a series of automated tools in step 5 to calibrate the results. They begin by adjusting the importance weights of the criteria identified in step 3 with the probabilities of occurrence from step 4. In step 6, the DMs use an Excel program of the model to calculate their individual scores for each project. They also use MAH in step 6 to come to a consensus in ranking all projects. During the interpretation steps 7 and 8, DMs consider the output from CROSS and make a final recommendation for management approval.

\section{Interaction Phase}

During the interaction phase, the DMs interact through automated systems with the stakeholder departments that must evaluate the projects. This phase consists of four steps.

First, the DMs identify the stakeholder departments that are to participate in the evaluation (for example, Safety, Reliability, and Systems Engineering) and ask management for its approval. The selection of stakeholders should be consistent with NASA's mission and objectives and with management's fiscalyear goals. In the second step, the DMs use the AHP and Expert Choice to weight the stakeholder departments (two rounds). Saaty (1972) introduced the AHP to help DMs to evaluate complex judgmental problems. The DMs assign numerical values to qualitative attributes by making trade-offs among them using a series of pairwise comparisons. Saaty argues that comparing two things is easier than comparing all the items in a list. The AHP also evaluates the DM's 
consistency and allows for revision of responses. The AHP has been widely used to rank order the alternatives of problems formulated in hierarchical structures (Saaty 1972, 1977a, 1977b, 1980, 1990a; Weiss and Rao 1987; Zahedi 1986). The AHP is a popular technique for determining weights in multicriteria problems (Shim 1989, Zahedi 1986), and it has been used to evaluate projects (Liberatore 1987, Lockett et al. 1984).

Schoemaker and Waid (1978) compared the AHP with three common multicriteria decision-making techniques: multiple regression, the multiattribute utility approach of Keeney and Raiffa (1976), and simple direct assessment. These methods require different types of judgments and different response modes, and they have different applications. Shoemaker and Waid showed that all four methods produce similar results, but each has advantages over the others. The AHP does not depend on consistency among preferences, while the multiattribute utility approach requires a transitive preference relation to construct a utility function. In addition, the AHP provides more detailed information on the pairwise comparisons with its systematic approach, and it is useful with criteria that cannot be measured. In theory, for repetitious decision-making situations, the multiattribute utility approach is more advantageous than the AHP because the same model can be used repeatedly. However, in practice, the utility function changes rapidly and hence has to be reevaluated. Thus, the multiattribute utility approach does not perform better than the AHP in practice. The AHP is also more appropriate than multiple regression and direct access for nonrepetitive decision-making situations because they lack measurable attributes.

Some in the OR community are critical of the AHP. Harker and Vargas (1987) show that the AHP has an axiomatic foundation, the eigenvector method fully represents the cardinal measurement of preferences, and the principles of hierarchical composition and rank reversal are valid. On the other hand, Dyer (1990a) questions the theoretical basis underlying the AHP and argues that the process can lead to preference reversals depending on the set of alternatives considered. In response, Saaty (1990b) explains why rank reversal is a positive feature when new reference points are introduced. CROSS uses the geometric aggregation rule to avoid rank reversal, which is of varying importance to different researchers (Dyer 1990a, 1990b; Harker and Vargas 1990; Saaty 1990b).

At the beginning of each CROSS evaluation cycle, the five DMs individually use the AHP software Expert Choice to weight the stakeholder departments by importance. Expert Choice synthesizes these judgments and provides anonymous feedback concerning individual and departmental weights (round 1). The DMs share their views and explain their weights in a group meeting. At the end of the meeting, the DMs may revise their judgments and assign different weights to the stakeholders because they do not agree on their importance (round 2). CROSS uses the normalized geometric means of the DMs' importance weights $\left(W_{i}\right)$ calculated at the end of the second round.

In the third step, the stakeholder departments identify their criteria and use Expert Choice to weight them for importance. The departments meet separately to develop their own criteria. Then, they use Expert Choice in brainstorming sessions to weight each criterion $\left(w_{i j}\right)$.

Assume stakeholder $i$ believes $c_{1}, c_{2}, \ldots, c_{I}$ are the $I$ criteria that contribute to the success of a project. The stakeholder assesses the relative importance of these criteria. The Expert Choice program asks the stakeholder to compare each possible pair of criteria $c_{j}, c_{k}$ and indicate which criterion is more important and by how much.

These judgments are represented by an $I \times I$ matrix:

$$
A=\left(a_{j k}\right) \quad(j, k=1,2, \ldots, I) .
$$

If the stakeholder judges $c_{j}$ to be equal in importance to $c_{k}$, then $a_{j k}=1$.

If the stakeholder judges $c_{j}$ to be more important than $c_{k}$, then $a_{j k}>1$.

If the stakeholder judges $c_{j}$ to be less important than $c_{k}$, then $a_{j k}<1$.

$$
a_{j k}=1 / a_{k j}, \quad a_{j k} \neq 0 .
$$

Thus, matrix $A$ is a reciprocal matrix with the entry $a_{j k}$ the inverse of the entry $a_{k j} . a_{j k}$ reflects the importance of $c_{j}$ compared with criteria $c_{k}$. For example, $a_{12}=1.25$ indicates that $c_{1}$ is 1.25 times as important as $c_{2}$. 
We can find the vector $w$ representing the relative weights of each of the $I$ criteria by computing the normalized eigenvector corresponding to the maximum eigenvalue of matrix $A$. An eigenvalue of $A$ is defined as $\lambda$, that satisfies the following matrix equation:

$$
A w=\lambda w,
$$

where $\lambda$ is a constant, called the eigenvalue, associated with the given eigenvector $w$. Saaty (1990a) shows that the best estimate of $w$ is the one associated with the maximum eigenvalue $\left(\lambda_{\max }\right)$ of the matrix $A$. Because the sum of the weights should be equal to 1.00 , the normalized eigenvector is used. Saaty's algorithm for obtaining this $w$ is incorporated in Expert Choice.

One of the AHP's advantages is that it assesses the consistency of the stakeholder's pairwise comparisons. Saaty (1990a) suggests a measure of consistency for the pairwise comparisons. When the judgments are perfectly consistent, the maximum eigenvalue $\left(\lambda_{\max }\right)$ should equal the number of criteria that are compared $(I)$. Typically, the responses are not perfectly consistent, and $\lambda_{\max }$ is greater than $I$. The larger the $\lambda_{\max }$, the greater is the degree of inconsistency. Saaty defines a consistency index as $\left(\lambda_{\max }-I\right) /(I-1)$ and provides a random index table for matrices of order 3 to 10. This random index is based on a simulation of a large number of randomly generated weights.

\begin{tabular}{lcccccccc}
\hline$n$ & 3 & 4 & 5 & 6 & 7 & 8 & 9 & 10 \\
\hline Random Index & 0.58 & 0.90 & 1.12 & 1.32 & 1.41 & 1.45 & 1.49 & 1.51
\end{tabular}

Saaty (1990a) recommends the calculation of a consistency ratio that is the ratio of consistency index to random index for the same order matrix. A consistency ratio of 0.10 or less is considered acceptable. When the consistency ratio is unacceptable, the pairwise comparisons are logically inconsistent and should be revised.

In the fourth step, stakeholder departments assign a probability of occurrence to each criterion for each project based on their expertise and past experience. DMs often use subjective probabilities in multicriteria decision making because they require no historical data (Schoemaker 1993, Schoemaker and Russo
1993, Vickers 1992, Weigelt and Macmillan 1988). Some researchers think that the difficulty of obtaining relevant historical information on which to base probabilities inhibits their use. However, one can use such probabilistic terms as possible, likely, and certain to elicit information verbally and then convert these terms into numeric probabilities (Brun and Teigen 1988, Budescu and Wallsten 1985, Tavana et al. 1997). Other commonly used approaches include reasoning (Koriat et al. 1980), scenario construction (Schoemaker 1993), and cross-impact analysis (Stover and Gordon 1978). Merkhofer (1987) and Spetzler and Stael von Holstein (1975) review probability-elicitation procedures that are used in practice.

CROSS uses the properties of binomial probabilities to assess each project. DMs commonly use binomial probabilities in multicriteria decision making because they can simplify the problem by analyzing possible outcomes as either occurring or not occurring. For example, Schoemaker (1993) assigns binomial probabilities to such factors as short-term interest rates exceeding 13 percent in the USA sometime during the next five years. Vickers (1992) also assigns binomial probabilities to similar factors, such as "Japanese car manufacturers gain at least 30 percent of the European market share" to examine the future of the European automobile industry.

CROSS uses probabilistic scales made up of such terms as possible, likely, and certain to elicit information and converts them into numeric probabilities as suggested by Tavana et al. (1997). Alternatively, CROSS permits the use of numeric probabilities rather than probabilistic terms. The committee sends all the stakeholder departments lists of all the projects under consideration, and the departments assign probabilities of occurrence to their sets of criteria for each project.

\section{Integration Phase}

In the integration phase, the members of each department process and integrate all the data collected during the interaction phase, using Excel, Expert Choice, ENTROSYS, and MAH.

In the fifth step, the members of each department use ENTROSYS to revise the importance weights of 
their criteria $\left(w_{i j}\right)$ identified in step 3 with the probabilities of occurrence from step 4. ENTROSYS, an Excel-based system, does all the calculations. Each criterion is an information source; therefore, the more information a criterion reveals, the more relevant it is. ENTROSYS uses this intrinsic information in conjunction with the stakeholder department weights. Consequently, the more information the $j$ th criterion and the $i$ th stakeholder reveal, the more relevant the criterion is to the decision analysis. Zeleny (1982) argues that this intrinsic information must be used in parallel with the initial weights the DMs assigned to various criteria. In other words, the overall importance weight of a criterion, $F_{i j}$, is directly related to the intrinsic weight, $f_{i j}$, reflecting the average intrinsic information developed by the probabilities of occurrence, and the subjective weight, $w_{i j}$, reflecting the DM's subjective assessment of its importance. ENTROSYS uses the probabilities of occurrence to measure this average intrinsic information.

The more different the probabilities of a criterion are for a set of projects, the larger is the contrast intensity of the criterion, and the greater is the amount of information transmitted by that criterion. Assume that the vector $p_{i j}=\left(p_{i j}^{1}, \ldots, p_{i j}^{q}\right)$ characterizes the set $P$ in terms of the $j$ th criterion for the $i$ th stakeholder and define

$$
P_{i j}=\sum_{m=1}^{q} p_{i j}^{m} \quad(i=1,2, \ldots, I \text { and } j=1,2, \ldots, J) .
$$

Then, the entropy measure of the $j$ th criterion for the $i$ th stakeholder is

$$
e\left(p_{i j}\right)=-K \sum_{m=1}^{q} \frac{p_{i j}^{m}}{p_{i j}} \ln \frac{p_{i l}^{m}}{p_{i j}},
$$

where $K>0$, ln is the natural logarithm, $0 \leq p_{i j}^{m} \leq 1$, and $e\left(p_{i j}\right) \geq 0$. When all $p_{i j}^{m}$ are equal for a given $i$ and $j$, then $p_{i j}^{m} / p_{i j}=1 / q$, and $e\left(p_{i j}\right)$ assumes its maximum value, which is $e_{\max }=\ln q$. By setting $K=1 / e_{\max }$, we achieve $0 \leq e\left(p_{i j}\right) \leq 1$. This normalization is necessary for meaningful comparisons. In addition, the total entropy is defined as

$$
E=\sum_{j=1}^{J} e\left(p_{i j}\right)
$$

The smaller $e\left(p_{i j}\right)$ is, the more information the $j$ th criterion transmits for the $i$ th stakeholder, and the larger $e\left(p_{i j}\right)$ is, the less information it transmits. When $e\left(p_{i j}\right)=e_{\max }=\ln q$, the $j$ th criterion for the $i$ th stakeholder transmits no useful information. Next, the intrinsic weight is calculated as

$$
f_{i j}=\frac{1}{I-E}\left[1-e\left(p_{i j}\right)\right] .
$$

Because $f_{i j}$ is inversely related to $e\left(p_{i j}\right)$, ENTROSYS uses $1-e\left(p_{i j}\right)$ instead of $e\left(p_{i j}\right)$ and normalizes it to make sure $0 \leq f_{i j} \leq 1$ and

$$
\sum_{j=1}^{J} f_{i j}=1 .
$$

The more different the probabilities of occurrences, $p_{i j}^{m}$, are, the larger $f_{i j}$ is and the more important the $j$ th criterion for the $i$ th stakeholder is. When all the probabilities of occurrence, $p_{i j}^{m}$, are equal, then $f_{i j}=0$. ENTROSYS multiplies the intrinsic weight, $f_{i j}$, by the subjective weight, $w_{i j}$, and normalizes the product to calculate the overall importance weight of the $j$ th criterion for the $i$ th stakeholder, $F_{i j}$ :

$$
F_{i j}=\frac{f_{i j} \cdot w_{i j}}{\sum_{j=1}^{J} f_{i j} \cdot w_{i j}} .
$$

When there is more than one probability estimate (n-ary criteria), ENTROSYS uses these probabilities to calculate the entropy within each alternative. These within-alternative intrinsic weights can influence the overall weight of the criteria. In other words, the overall importance weight for an n-ary criterion, $F_{i j}$, is related to its between-alternative intrinsic weight, $f_{i j}$, the subjective weight, $w_{i j}$, and the within-alternative intrinsic weight.

In step 6, the DMs use Excel to calculate the success factor of each project and MAH to provide a consensus ranking of the projects. The DMs use Microsoft Excel to calculate the success factor of each project $\left(S^{m}\right)$ by using Equation (4) and the information the DMs and stakeholders provided in the previous steps. Projects with high success factors are preferred to projects with low success factors. Excel uses the success factors to rank the projects for each DM. Dyer and Forman (1992) discuss several approaches to 
combining individual preferences into a joint representation of the group's preferences. First, the group members may try to reconcile differences of opinion by searching for consensus judgments. Second, they may subject intermediate judgments between extreme standpoints to a vote. Third, they may aggregate these decomposed judgments through normative averaging procedures. Finally, they may average the results of the individual models by assigning weights to the group members. All of these approaches suffer from some drawbacks. In CROSS, I used Microsoft Excel and MAH to provide a consensus ranking of the projects. MAH, proposed by Beck and Lin (1983), forms consensus orderings that reflect collective DM agreement given ordinal or cardinal project rankings. Similarly, one could use normative averaging procedures to combine individual rankings. However, normative aggregation procedures (Aczel and Saaty 1983, Steeb and Johnson 1981) provide little stimulus for the exchange of opinions, and if the DMs' logic is not clear, the members of the group may have difficulty committing themselves to the synthesized outcome. The reasons we chose MAH as the consensus ranking procedure were its simplicity, flexibility, and general performance.

If each of the $d$ DMs has ranked $q$ projects, and their opinions are to be valued equally, the MAH seeks a consensus ranking of the projects for the group as a whole. The MAH defines an agreement matrix, $A$, in which each element $a_{m n}$ represents the number of DMs who prefer project $m$ to project $n$. Strict preference is important. A DM who is indifferent between $m$ and $n$ is not counted in $a_{m n}$. The sum of $a_{m n}$ for each project macross all columns represents the positive preference vector, $C$, where

$$
C_{m}=\sum_{n=1}^{q} a_{m n} \quad(m=1,2, \ldots, q)
$$

Similarly, the sum of $a_{m n}$ for each project across all rows represents the negative preference vector, $R$, where

$$
R_{m}=\sum_{n=1}^{q} a_{m n} \quad(m=1,2, \ldots, q) .
$$

If for project $m, C_{m}=0$, implying that no DM prefers project $m$ to any other project, $m$ is placed at the bottom (in subsequent iterations, at the next available position at the bottom) of the final consensus ranking. However, if for project $m, R_{m}=0$, implying that no DM prefers any other project over $m$, project $m$ is placed at the top (in subsequent iterations, at the next available position at the top) of the ranking.

When there are no zero values in either $C$ or $R$, MAH calculates the difference in total DM agreement and disagreement $\left(C_{m}-R_{m}\right)$ for each project and considers project $m$ with the largest absolute difference $\left|C_{m}-R_{m}\right|$. If $\left(C_{m}-R_{m}\right)$ is positive, MAH places project $m$ in the next available position at the top of the final consensus ranking, and if the difference is negative, it places project $m$ in the next available position at the bottom of the consensus ranking. MAH breaks ties arbitrarily. Once MAH assigns a project a position in the final consensus ranking, it eliminates that project from further consideration. The remaining projects form a new matrix, and MAH repeats the process until it has ranked all the projects.

CROSS is intended to promote consensus among DMs. The term consensus is mathematically vague. If we assume that consensus means collective opinion, I suggest a weighted sum of project-success factors across all the DMs for a cardinal ranking of projects. However, the KSC shuttle project engineering office wanted the final ranking of the projects to be closest to the $\mathrm{DMs}^{\prime}$ preferences and also to yield the greatest number of agreements. Beck and Lin's (1983) definition of agreement meets these requirements. If a DM ranks project $m$ above project $n$ and project $m$ is also ranked above project $n$ in the final consensus ranking, this counts as one agreement. In other words, if a DM's ranking order of projects $m$ and $n$ is the same as that in the final consensus ranking, the final ranking has yielded agreement; otherwise, it has yielded disagreement.

\section{Interpretation Phase}

During the interpretation phase, DMs present all the synthesized data to the committee for a final decision. This phase includes two steps.

First, in step 7, the DMs discuss the consensus and committee rankings and recommend a final ranking of projects to management. After the DMs meet, they develop a spreadsheet model and use it to conduct 
sensitivity analysis concerning the weights and probabilities of occurrence. The DMs sometimes discuss the impact of changes in model assumptions on the rankings. In addition, they often disagree about the probabilities of occurrence, which reflect the degree of belief that an uncertain event will occur. After the sensitivity analyses, the DMs forward a final recommendation that includes a ranking of all projects to management for approval. Finally, in step 8, management reviews the $\mathrm{DMs}^{\prime}$ ranking of projects, carefully considers the organizational implications, and makes the final decision.

\section{The Model}

To formulate an algebraic model, let us assume the following:

$S^{m}=$ the project success factor of the $m$ th project $(m=1,2, \ldots, q)$.

$W_{i}=$ the importance weight of the $i$ th stakeholder $(i=1,2, \ldots, I)$.

$F_{i j}=$ the overall importance weight of the $j$ th criterion for the $i$ th stakeholder $(i=1,2, \ldots, I$ and $j=1,2, \ldots, J)$.

$P_{i j}^{m}=$ the $m$ th probability of occurrence of the $j$ th criterion for the $i$ th stakeholder and the $m$ th project $(m=1,2, \ldots, q ; i=1,2, \ldots, I$; and $j=1,2, \ldots, J)$.

$q=$ the number of projects.

$I=$ the number of stakeholders.

$J=$ the number of criteria for the $i$ th stakeholder.

Given the above notations, the project-success factor of the $m$ th project is

$$
S^{m}=\sum_{i=1}^{I} W_{i}\left(\sum_{j=1}^{J} F_{i j}\left(P_{i j}^{m}\right)\right),
$$

where $1 \geq S^{m} \geq 0,0 \leq P_{i j}^{m} \leq 1, \quad \sum_{i=1}^{I} W_{i}=1$, and $\sum_{j=1}^{J} F_{i j}=1$.

\section{A Case Study}

To illustrate the procedure and its usefulness, I will describe a disguised actual case study at NASA - KSC. In this case, the committee received requests for funding for 10 projects (Table 1 ). A budget of $\$ 15$ million would be needed to fund all 10 projects.

\begin{tabular}{clr} 
Project Number & \multicolumn{1}{c}{ Project } & Cost $(\$)$ \\
\hline 1 & Hubble & $1,778,000$ \\
2 & Photovoltaic & $1,908,000$ \\
3 & Airlock & $1,515,000$ \\
4 & Babaloon & $1,949,000$ \\
5 & Planet-Finder & $1,266,000$ \\
6 & Nebula & $1,348,000$ \\
7 & Solar & $1,176,000$ \\
8 & Truss & $1,347,000$ \\
9 & Centrifuge & $1,790,000$ \\
10 & Tether & 961,000 \\
Total & & $15,038,000$
\end{tabular}

Table 1: A budget of $\$ 15$ million would be needed to fund all 10 of these projects under consideration.

However, budgetary constraints limited spending to $\$ 6$ million.

The process began with an initial meeting of the DMs who were appointed by KSC management to an executive committee for a two-year term. During the interaction phase, the DMs began by identifying the stakeholders. After several meetings, they identified six stakeholder departments: Safety, Systems Engineering, Cost Savings, Process Enhancement, Reliability, and Implementation. The DMs then used Expert Choice to weight the stakeholder departments for importance. Next, they synthesized the individual judgments from the first round and considered the anonymous feedback (Table 2). The DMs then met to share their views in a brainstorming session. At the end of the session, they had an opportunity to revise the importance weights they had assigned to the stakeholder departments (Table 2). Some did so, for example, DM $A$ reduced his weight for safety from 0.59 to 0.45 after reviewing the group normalized mean of 0.50 for safety in the first round. The DMs used the normalized means from the second round in CROSS for the final evaluation of the projects.

The reliability department identified 10 criteria, the implementation department and the costsavings department each identified seven criteria, the safety department and the systems engineering department each identified five criteria, and the process-enhancement department identified four criteria to be included in CROSS (Table 3). 
TAVANA

CROSS

Round 1

\begin{tabular}{|c|c|c|c|c|c|c|c|}
\hline \multirow[b]{2}{*}{ Decision Maker } & \multicolumn{7}{|c|}{ Stakeholder Departments } \\
\hline & Safety & Systems Engineering & Cost Savings & Process Enhancement & Reliability & Implementation & Consistency Ratio \\
\hline A & 0.59 & 0.11 & 0.11 & 0.05 & 0.08 & 0.06 & 0.06 \\
\hline$B$ & 0.44 & 0.08 & 0.10 & 0.05 & 0.18 & 0.15 & 0.05 \\
\hline C & 0.40 & 0.21 & 0.08 & 0.06 & 0.21 & 0.04 & 0.06 \\
\hline$D$ & 0.39 & 0.13 & 0.10 & 0.07 & 0.26 & 0.05 & 0.05 \\
\hline$E$ & 0.61 & 0.14 & 0.05 & 0.06 & 0.09 & 0.05 & 0.04 \\
\hline Geometric Mean & 0.48 & 0.13 & 0.08 & 0.06 & 0.15 & 0.06 & \\
\hline Normalized Mean & 0.50 & 0.13 & 0.09 & 0.06 & 0.15 & 0.06 & \\
\hline \multicolumn{8}{|c|}{ Round 2} \\
\hline & \multicolumn{7}{|c|}{ Stakeholder Departments } \\
\hline Decision Maker & Safety & Systems Engineering & Cost Savings & Process Enhancement & Reliability & Implementation & Consistency Ratio \\
\hline$A$ & 0.45 & 0.22 & 0.14 & 0.09 & 0.05 & 0.05 & 0.02 \\
\hline B & 0.34 & 0.08 & 0.12 & 0.07 & 0.20 & 0.19 & 0.02 \\
\hline C & 0.41 & 0.25 & 0.08 & 0.06 & 0.17 & 0.03 & 0.03 \\
\hline$D$ & 0.38 & 0.13 & 0.09 & 0.06 & 0.28 & 0.06 & 0.02 \\
\hline $\mathrm{E}$ & 0.59 & 0.13 & 0.06 & 0.06 & 0.10 & 0.06 & 0.02 \\
\hline Geometric Mean & 0.43 & 0.15 & 0.09 & 0.07 & 0.14 & 0.06 & \\
\hline Normalized Mean & 0.45 & 0.16 & 0.10 & 0.07 & 0.15 & 0.07 & \\
\hline
\end{tabular}

Table 2: The DMs used Expert Choice to weight the stakeholder departments for importance. They synthesized the individual judgments from the first round and considered the anonymous feedback. They had an opportunity to revise their importance weights. The DMs used the normalized means from the second round for the final evaluation of the projects.

Next, the DMs asked each stakeholder department to identify a set of criteria to be used in the evaluation process and to assess their importance weights. Each department held separate meetings and developed its set of criteria. Then, they used Expert Choice to weight their criteria. I advised them to record their consistency ratio and make sure it was below 0.10 as suggested by Saaty (1972).

The stakeholder departments then held separate meetings and developed a probability of occurrence for each criterion identified in the previous step (Table 4). While some stakeholders used numerical probabilities, most preferred the approach proposed by Tavana et al. (1997). For example, the safety department was quite certain (90 percent) that death or serious injury could be eliminated in Hubble while they believed it was somewhat likely (60 percent) this threat could be eliminated in Photovoltaic.
In the integration phase, the stakeholders revised the initial importance weights they had suggested using the intrinsic weight (Zeleny 1982) (Table 5). The intrinsic weight quantifies the contrast intensity and derives objective weights for the criteria. If all projects have the same probability for a criterion, the criterion can be eliminated from further consideration. Alternately, if all projects have similar probabilities, the weight assigned to a criterion can be smaller. On the other hand, when all projects have very different probabilities, the criterion is viewed as more important. The members of each department used an Excel-based system called ENTROSYS to perform all necessary mathematical calculations. For example, the safety department provided an initial weight of 0.564 for eliminating the possibility of death or serious injury. The safety department also provided probabilities of occurrence of this criterion for the 10 projects. 
TAVANA

\begin{tabular}{|c|c|c|c|}
\hline Stakeholder Departments & Criteria & Description & Weight \\
\hline \multirow[t]{5}{*}{ Safety } & S-DSI & Eliminating the possibility of death or serious injury & 0.564 \\
\hline & S-LOF & Eliminating the possibility of loss of flight hardware, facility, or GSE & 0.239 \\
\hline & S-PID & Eliminating the possibility of personal injury or flight hardware, facility, or GSE damage & 0.118 \\
\hline & S-SVS & Eliminating the possibility of a serious violation of safety, health, or environmental federal/state & 0.047 \\
\hline & S-DVS & Eliminating the possibility of a deminius violation of safety, health, or environmental & 0.032 \\
\hline \multirow[t]{5}{*}{ Systems Engineering } & E-LSP & Reducing or eliminating the possibility of launch slippage & 0.553 \\
\hline & E-NTR & Supporting program for near-term requirements & 0.171 \\
\hline & E-ONA & Eliminating occurrence of nonsupport activities & 0.132 \\
\hline & E-FAL & Reducing or eliminating a system failure & 0.107 \\
\hline & $\mathrm{E}-\mathrm{OBS}$ & Eliminating reliance on identified obsolete technology & 0.037 \\
\hline \multirow[t]{7}{*}{ Cost Savings } & C-LAB & Reducing or eliminating unnecessary labor dollars & 0.391 \\
\hline & C-MAT & Reducing or eliminating unnecessary material dollars & 0.197 \\
\hline & C-TSI & Utilizing time-sensitive implementation methodology & 0.147 \\
\hline & C-MPC & Meeting the proposed cost & 0.105 \\
\hline & C-MPS & Meeting the proposed schedule & 0.086 \\
\hline & C-ROM & Reducing operations and maintenance costs & 0.045 \\
\hline & C-CON & Meeting contractual obligations & 0.029 \\
\hline \multirow[t]{4}{*}{ Process Enhancement } & P-LPL & Reducing labor hours used on the launch pad & 0.563 \\
\hline & P-LPT & Reducing launch and processing time & 0.246 \\
\hline & P-LPA & Improving launch pad accessibility & 0.124 \\
\hline & P-LPH & Reducing or eliminating hardware and materials expended on the launch pad & 0.067 \\
\hline \multirow[t]{10}{*}{ Reliability } & R-SFP & Eliminating critical single failure points (CSFPs) & 0.412 \\
\hline & R-CFP & Reducing the possibility of failure propagation to other components or systems & 0.194 \\
\hline & R-MTR & Improving mean time to repair (MTTR) & 0.110 \\
\hline & R-IFI & Improving Fault Identification and Fault Isolation (FI/FI) & 0.092 \\
\hline & R-SIM & Providing for a simpler system & 0.053 \\
\hline & R-AMT & Improving access for maintenance tasks & 0.049 \\
\hline & $\mathrm{R}$-TBF & Increasing mean time between failures (MTBFs) & 0.040 \\
\hline & R-ETT & Reducing support equipment, special tools, and special training requirements & 0.030 \\
\hline & $\mathrm{R}-\mathrm{COT}$ & Providing for the use of standard commercial off-the-shelf (COTS) parts & 0.010 \\
\hline & $\mathrm{R}-\mathrm{EQP}$ & Providing for equipment interchangability & 0.010 \\
\hline \multirow[t]{7}{*}{ Implementation } & I-MSA & Reducing or eliminating multisite applicability & 0.423 \\
\hline & I-IMI & Reducing or eliminating the possibility of interference in implementation & 0.195 \\
\hline & I-FMC & Reducing or eliminating the possibility of flight manifest changes & 0.137 \\
\hline & I-MSC & Reducing or eliminating the effects on multisystem configuration systems & 0.116 \\
\hline & $\mathrm{I}-\mathrm{EOH}$ & Reducing or eliminating the possibility of equipment and occupational hazards & 0.065 \\
\hline & I-SSR & Reducing or eliminating site-specific restrictions & 0.033 \\
\hline & $\mathrm{I}-\mathrm{TCH}$ & Meeting new technology considerations & 0.031 \\
\hline
\end{tabular}

Table 3: The stakeholder departments identified a set of criteria to be used in the evaluation process and used Expert Choice to weight their criteria $\left(w_{i j}\right)$.

The stakeholder departments used ENTROSYS to calculate an intrinsic weight of 0.232 for these probabilities. Next, they calculated the overall weight for this criterion (0.666) using Equation (3).

Next, the DMs used another Excel-based program to calculate the project-success factor of each project using Equation (4). The system provides a set of rankings for each individual DM (Table 6).

Next, the DMs used MAH to develop a consensus ranking of projects using the procedure described for step 6 (Table 7). They collectively performed some sensitivity analyses on the importance weights

INTERFACES

Vol. 33, No. 3, May-June 2003 
TAVANA

CROSS

Project

\begin{tabular}{|c|c|c|c|c|c|c|c|c|c|c|c|}
\hline \multirow[b]{2}{*}{ Stakeholder Departments } & \multirow[b]{2}{*}{ Criteria } & \\
\hline & & Hubble & Photovoltaic & Airlock & Babaloon & Planet-Finder & Nebula & Solar & Truss & Centrifuge & Tether \\
\hline \multirow[t]{5}{*}{ Safety } & S-DSI & 0.90 & 0.60 & 0.30 & 0.90 & 0.20 & 0.80 & 0.70 & 0.60 & 0.90 & 0.40 \\
\hline & S-LOF & 0.30 & 0.70 & 0.90 & 0.70 & 0.60 & 0.90 & 0.70 & 0.90 & 1.00 & 0.50 \\
\hline & S-PID & 0.80 & 0.20 & 0.60 & 1.00 & 0.70 & 0.70 & 0.70 & 0.70 & 0.90 & 1.00 \\
\hline & S-SVS & 0.70 & 0.90 & 0.80 & 0.20 & 0.80 & 0.90 & 0.60 & 1.00 & 0.30 & 0.50 \\
\hline & S-DVS & 0.60 & 0.90 & 0.30 & 0.40 & 1.00 & 0.60 & 1.00 & 0.80 & 1.00 & 0.20 \\
\hline \multirow[t]{5}{*}{ Systems Engineering } & E-LSP & 0.10 & 0.60 & 0.00 & 0.50 & 0.70 & 0.50 & 0.40 & 0.20 & 0.10 & 0.10 \\
\hline & E-NTR & 0.70 & 0.80 & 0.70 & 0.50 & 0.00 & 1.00 & 0.00 & 0.00 & 0.00 & 0.00 \\
\hline & E-ONA & 0.30 & 0.10 & 0.00 & 0.40 & 1.00 & 0.00 & 0.40 & 0.80 & 0.30 & 0.30 \\
\hline & E-FAL & 0.70 & 1.00 & 0.00 & 0.90 & 0.00 & 0.30 & 0.80 & 0.00 & 0.00 & 0.90 \\
\hline & $\mathrm{E}-\mathrm{OBS}$ & 0.10 & 0.10 & 1.00 & 0.00 & 0.00 & 0.00 & 0.00 & 0.00 & 0.00 & 0.00 \\
\hline \multirow[t]{7}{*}{ Cost Savings } & C-LAB & 0.70 & 0.30 & 0.30 & 0.30 & 0.30 & 0.70 & 0.50 & 0.50 & 0.50 & 0.40 \\
\hline & C-MAT & 0.60 & 0.60 & 0.80 & 0.60 & 0.90 & 0.60 & 0.70 & 0.60 & 0.80 & 0.30 \\
\hline & C-TSI & 0.80 & 0.80 & 0.80 & 0.80 & 0.80 & 0.80 & 0.80 & 0.80 & 0.80 & 0.80 \\
\hline & C-MPC & 0.60 & 0.70 & 0.60 & 0.40 & 0.70 & 0.70 & 0.60 & 0.30 & 0.70 & 0.20 \\
\hline & C-MPS & 0.50 & 0.50 & 0.50 & 0.60 & 0.50 & 0.60 & 0.50 & 0.50 & 0.50 & 0.50 \\
\hline & C-ROM & 0.70 & 0.70 & 0.60 & 0.80 & 0.10 & 0.20 & 0.10 & 0.50 & 0.60 & 0.60 \\
\hline & C-CON & 0.70 & 0.90 & 1.00 & 0.80 & 1.00 & 0.30 & 1.00 & 0.70 & 1.00 & 0.80 \\
\hline \multirow[t]{4}{*}{ Process Enhancement } & P-LPL & 0.20 & 0.60 & 0.70 & 0.20 & 0.40 & 0.20 & 0.20 & 0.20 & 0.20 & 0.40 \\
\hline & P-LPT & 0.80 & 1.00 & 0.20 & 0.30 & 0.60 & 0.60 & 0.80 & 0.40 & 0.20 & 0.60 \\
\hline & P-LPA & 0.10 & 0.10 & 0.30 & 0.10 & 0.80 & 0.10 & 0.10 & 0.10 & 0.30 & 0.10 \\
\hline & P-LPH & 0.10 & 0.40 & 1.00 & 1.00 & 0.10 & 0.40 & 0.10 & 0.10 & 0.10 & 0.20 \\
\hline \multirow[t]{10}{*}{ Reliability } & R-SFP & 0.80 & 0.00 & 0.90 & 0.00 & 0.00 & 0.90 & 0.00 & 0.00 & 0.70 & 0.00 \\
\hline & R-CFP & 0.90 & 0.70 & 0.00 & 0.80 & 0.70 & 0.80 & 1.00 & 0.00 & 0.20 & 0.00 \\
\hline & R-MTR & 0.70 & 0.90 & 0.70 & 1.00 & 0.70 & 0.60 & 0.40 & 0.70 & 0.60 & 0.30 \\
\hline & R-IFI & 0.70 & 0.70 & 0.00 & 0.80 & 0.50 & 0.70 & 0.70 & 0.70 & 0.80 & 0.00 \\
\hline & R-SIM & 0.80 & 0.60 & 0.70 & 0.00 & 0.00 & 0.80 & 0.60 & 0.70 & 0.10 & 0.70 \\
\hline & R-AMT & 0.60 & 0.70 & 0.70 & 0.90 & 0.70 & 0.80 & 0.80 & 0.00 & 0.00 & 0.60 \\
\hline & $\mathrm{R}-\mathrm{TBF}$ & 0.70 & 0.40 & 0.00 & 0.00 & 0.30 & 0.40 & 0.60 & 0.70 & 0.70 & 0.80 \\
\hline & R-ETT & 0.00 & 0.70 & 0.70 & 1.00 & 0.70 & 0.70 & 0.70 & 0.00 & 0.70 & 0.70 \\
\hline & R-COT & 0.90 & 0.20 & 0.70 & 0.80 & 0.50 & 0.20 & 0.30 & 0.90 & 0.10 & 0.60 \\
\hline & $\mathrm{R}-\mathrm{EQP}$ & 0.80 & 0.70 & 0.80 & 0.90 & 0.20 & 0.00 & 0.80 & 0.60 & 0.80 & 0.00 \\
\hline \multirow[t]{7}{*}{ Implementation } & I-MSA & 0.00 & 0.80 & 0.50 & 0.90 & 0.50 & 0.00 & 0.90 & 0.80 & 0.70 & 0.80 \\
\hline & I-IMI & 1.00 & 0.90 & 0.50 & 0.70 & 0.40 & 0.90 & 0.20 & 0.90 & 0.80 & 0.90 \\
\hline & I-FMC & 0.90 & 0.90 & 0.50 & 0.70 & 0.40 & 0.80 & 0.20 & 0.80 & 0.40 & 0.90 \\
\hline & I-MSC & 0.90 & 0.80 & 0.70 & 0.80 & 0.80 & 1.00 & 0.60 & 0.60 & 0.80 & 0.70 \\
\hline & I-EOH & 1.00 & 0.50 & 0.40 & 0.60 & 0.50 & 1.00 & 0.50 & 0.80 & 0.70 & 0.80 \\
\hline & I-SSR & 0.90 & 0.80 & 0.50 & 0.70 & 0.50 & 1.00 & 0.30 & 0.70 & 0.60 & 0.60 \\
\hline & I-TCH & 0.00 & 0.30 & 0.10 & 0.10 & 0.10 & 0.00 & 0.00 & 0.10 & 0.10 & 0.40 \\
\hline
\end{tabular}

Table 4: The stakeholder departments developed a probability of occurrence $\left(P_{i j}\right)$ for each criterion under each project.

and probabilities of occurrence. Given the $\$ 6$ million budget constraint, the DMs recommended funding the Nebula, Hubble, and Centrifuge projects with a cumulative cost of $\$ 4,916,000$.
Finally, after receiving the final rankings of the projects, management can approve this recommendation or adjust the list. If the committee's recommendations do not exhaust the entire budget, 


\begin{tabular}{|c|c|c|c|c|}
\hline $\begin{array}{l}\text { Stakeholder } \\
\text { Departments }\end{array}$ & Criteria & $\begin{array}{c}\text { Initial } \\
\text { Weight }\end{array}$ & $\begin{array}{l}\text { Intrinsic } \\
\text { Weight }\end{array}$ & $\begin{array}{l}\text { Overall } \\
\text { Weight }\end{array}$ \\
\hline \multirow[t]{5}{*}{ Safety } & S-DSI & 0.564 & 0.232 & 0.666 \\
\hline & S-LOF & 0.239 & 0.120 & 0.146 \\
\hline & S-PID & 0.118 & 0.148 & 0.089 \\
\hline & S-SVS & 0.047 & 0.224 & 0.054 \\
\hline & S-DVS & 0.032 & 0.275 & 0.045 \\
\hline \multirow[t]{5}{*}{ Systems Engineering } & E-LSP & 0.553 & 0.085 & 0.369 \\
\hline & E-NTR & 0.171 & 0.192 & 0.258 \\
\hline & E-ONA & 0.132 & 0.108 & 0.112 \\
\hline & $\mathrm{E}-\mathrm{FAL}$ & 0.107 & 0.151 & 0.127 \\
\hline & $\mathrm{E}-\mathrm{OBS}$ & 0.037 & 0.464 & 0.135 \\
\hline \multirow[t]{7}{*}{ Cost Savings } & C-LAB & 0.391 & 0.158 & 0.504 \\
\hline & C-MAT & 0.197 & 0.092 & 0.148 \\
\hline & C-TSI & 0.147 & 0.000 & 0.000 \\
\hline & C-MPC & 0.105 & 0.170 & 0.146 \\
\hline & C-MPS & 0.086 & 0.008 & 0.006 \\
\hline & C-ROM & 0.045 & 0.459 & 0.169 \\
\hline & C-CON & 0.029 & 0.112 & 0.027 \\
\hline \multirow[t]{4}{*}{ Process Enhancement } & P-LPL & 0.563 & 0.129 & 0.423 \\
\hline & P-LPT & 0.246 & 0.113 & 0.162 \\
\hline & P-LPA & 0.124 & 0.353 & 0.256 \\
\hline & P-LPH & 0.067 & 0.406 & 0.159 \\
\hline \multirow[t]{10}{*}{ Reliability } & R-SFP & 0.412 & 0.296 & 0.706 \\
\hline & R-CFP & 0.194 & 0.136 & 0.153 \\
\hline & R-MTR & 0.110 & 0.015 & 0.010 \\
\hline & R-IFI & 0.092 & 0.074 & 0.040 \\
\hline & R-SIM & 0.053 & 0.097 & 0.030 \\
\hline & R-AMT & 0.049 & 0.075 & 0.021 \\
\hline & R-TBF & 0.040 & 0.087 & 0.020 \\
\hline & R-ETT & 0.030 & 0.074 & 0.013 \\
\hline & $\mathrm{R}-\mathrm{COT}$ & 0.010 & 0.055 & 0.003 \\
\hline & $\mathrm{R}-\mathrm{EQP}$ & 0.010 & 0.090 & 0.005 \\
\hline \multirow[t]{7}{*}{ Implementation } & I-MSA & 0.423 & 0.233 & 0.684 \\
\hline & I-IMI & 0.195 & 0.069 & 0.094 \\
\hline & I-FMC & 0.137 & 0.074 & 0.071 \\
\hline & I-MSC & 0.116 & 0.011 & 0.009 \\
\hline & I-EOH & 0.065 & 0.042 & 0.019 \\
\hline & I-SSR & 0.033 & 0.044 & 0.010 \\
\hline & I-TCH & 0.031 & 0.527 & 0.114 \\
\hline
\end{tabular}

Table 5: The stakeholders used ENTROSYS to revise the initial importance weights $\left(w_{i j}\right)$ they had suggested. The program used Equation (3) and calculated the intrinsic weights $\left(f_{i j}\right)$ and the overall importance weights $\left(F_{i j}\right)$.

it can exercise one of two options. It can fund a project that fell below the cutoff point (without breaking the budget) or it can transfer the unused budget to a different funding program within KSC. In this example, after approving $\$ 4,916,000$ spending on
Nebula, Hubble, and Centrifuge, it could either fund Tether or transfer the remaining $\$ 1,084,000$ to another program within KSC.

\section{Managerial Implications}

Prior to implementation of CROSS and dissatisfied with the current evaluation process, KSC management identified explicitness, consistency, simplicity, flexibility, participation, decision-process quality, and decision quality as important attributes of the evaluation process. I pretested a seven-item questionnaire and used it to measure committee members' perceptions of the current evaluation process. I administered the same questionnaire to the committee members after the first year and after the second-year of implementation of CROSS. This questionnaire contained a definition for each attribute and a seven-point Likert scale with 1 indicating strong disagreement, 4 indifference, and 7 strong agreement (Lewis and Butler 1993). I obtained before and after mean and standard deviations (Table 8).

I used a one-sided Wilcoxon signed ranks test with 15 subjects and $\alpha=0.05$ to compare the committee ratings. All the pre-CROSS means were significantly smaller than the first year means with the exception of simplicity. Statistical analysis of pre-CROSS and second-year ratings revealed similar results. However, there was no statistical difference between the pre-CROSS and the second year simplicity scores at the 0.05 significance. During the second year, the committee members felt more comfortable with CROSS. All the committee members were quite technically oriented and held at least undergraduate engineering degrees. Although they felt comfortable with the technical details of the model, people who were less technically sophisticated might not. While some of the detailed work can be done with the help of experts and computers, the DM must understand and interpret the results for the decision environment. When I implement CROSS with an appropriate user interface, I can make the technical details transparent to users.

I performed sensitivity analysis using the methodology proposed by Triantaphyllou and Sanchez 
TAVANA

CROSS

\begin{tabular}{lccccccccrr}
$\begin{array}{l}\text { Decision } \\
\text { Maker }\end{array}$ & Rank-1 & Rank-2 & Rank-3 & Rank-4 & Rank-5 & Rank-6 & Rank-7 & Rank-8 & Rank-9 & Rank-10 \\
\hline A & 6 & 4 & 1 & 9 & 2 & 7 & 8 & 3 & 5 & 10 \\
B & 9 & 6 & 1 & 4 & 2 & 7 & 3 & 8 & 10 & 5 \\
C & 6 & 1 & 4 & 9 & 2 & 7 & 3 & 8 & 5 & 10 \\
D & 6 & 1 & 9 & 4 & 3 & 2 & 7 & 8 & 5 & 10 \\
E & 6 & 9 & 4 & 1 & 7 & 2 & 8 & 3 & 10 & 5
\end{tabular}

Table 6: The DMs used an Excel-based program to calculate the project-success factor of each project using Equation (4). The system provided a set of rankings for each individual DM. In these rankings, project 1 is Hubble, $\mathbf{2}$ is Photovoltaic, ..., and 10 is Tether.

(1997). Considering a decision problem with $M$ alternatives and $N$ criteria, I calculated the minimum change required in the weight of a criterion to cause rank reversal among alternatives. In performing this calculation, I assumed that $\delta_{k, i, j}(1 \leq i \leq j \leq M$ and $1 \leq k \leq N)$ is the minimum change in the current weight $\left(W_{k}\right)$ of criterion $C_{k}$ that reverses the ranking of alternatives $A_{i}$ and $A_{j}$, and I defined $\delta_{k, i, j}^{\prime}=\delta_{k, i, j} \times 100 / W_{k}$, for any $1 \leq i<j \leq M$ and $1 \leq$ $k \leq N$, where $\delta_{k, i, j}^{\prime}$ is the change in relative terms. One can perform sensitivity analysis on several variables in the example. I chose the safety criteria weight for DM $A$ for illustration purposes (Table 9).

I performed similar sensitivity analyses on the remaining criteria and the probabilities of occurrence. The results confirm the robustness of the model

\begin{tabular}{clrrr} 
Rank & Project & $\begin{array}{c}\text { Project } \\
\text { Number }\end{array}$ & Cost & Cumulative Costs \\
\hline & Nebula & 6 & $1,348,000$ & $1,348,000$ \\
1 & Hubble & 1 & $1,778,000$ & $3,126,000$ \\
2 & Centrifuge & 9 & $1,790,000$ & $4,916,000$ \\
\hline 3 & Babaloon & 4 & $1,949,000$ & $6,865,000$ \\
5 & Photovoltaic & 2 & $1,908,000$ & $8,773,000$ \\
6 & Solar & 7 & $1,176,000$ & $9,949,000$ \\
7 & Airlock & 3 & $1,515,000$ & $11,464,000$ \\
8 & Truss & 8 & $1,347,000$ & $12,811,000$ \\
9 & Planet-Finder & 5 & $1,266,000$ & $14,077,000$ \\
10 & Tether & 10 & 961,000 & $15,038,000$
\end{tabular}

Table 7: The DMs used MAH to develop a consensus ranking of projects. Given the $\$ 6$ million budget constraint, the DMs recommended funding the Nebula, Hubble, and Centrifuge projects with a cumulative cost of $\$ 4,916,000$. because several changes in the relative weights or the probabilities of occurrence must occur simultaneously before any rank reversal. Furthermore, the rank reversal for one DM does not necessarily result in reversal of final project rankings. In addition, Expert Choice also allows for sensitivity analysis. Users can graphically alter their judgments and see on the screen how that changes the relative weights.

In summary, the committee was quite satisfied with the decision outcome using CROSS. In addition, management had confidence in the committee's final rankings. Prior to implementation of CROSS, the committee's rankings always prompted lengthy management debates and reversal. Normally, management had eliminated 25 to 30 percent of the projects recommended by the committee from the final list and replaced them with other, lower-ranked projects. During the first year of implementation of CROSS, the committee selected 12 projects from the list of 41 reviewed. During the second year, the committee reviewed 30 projects and selected nine. Management approved all 12 projects during the first year and all nine during the second year.

\section{Conclusion}

CROSS is not intended to replace human judgment in project evaluation at KSC. In fact, human judgment is its basic input. CROSS helps DMs to think systematically about complex project-selection problems and improves the quality of their decisions. It is almost impossible to obtain objective data on the characteristics of most advanced-technology projects because of inherent uncertainties. However, experienced DMs can often make fairly accurate estimates of values for 


\begin{tabular}{|c|c|c|c|c|c|c|}
\hline \multirow[b]{3}{*}{ Item } & & & \multicolumn{4}{|c|}{ Post-CROSS } \\
\hline & \multicolumn{2}{|c|}{ Pre-CROSS } & \multicolumn{2}{|c|}{ First Year } & \multicolumn{2}{|c|}{ Second Year } \\
\hline & Mean & $\begin{array}{l}\text { Standard } \\
\text { Deviation }\end{array}$ & Mean & $\begin{array}{l}\text { Standard } \\
\text { Deviation }\end{array}$ & Mean & $\begin{array}{l}\text { Standard } \\
\text { Deviation }\end{array}$ \\
\hline Explicitness & 2.00 & 0.53 & 5.60 & 0.83 & 6.00 & 0.76 \\
\hline Consistency & 2.40 & 0.83 & 6.00 & 0.53 & 6.20 & 0.56 \\
\hline Simplicity & 5.00 & 0.93 & 4.40 & 0.74 & 4.80 & 1.15 \\
\hline Flexibility & 1.80 & 0.77 & 5.40 & 0.74 & 5.80 & 0.86 \\
\hline Decision-Maker Participation & 2.40 & 0.63 & 6.40 & 0.74 & 6.40 & 0.51 \\
\hline Decision-Process Quality & 2.20 & 0.68 & 6.20 & 0.68 & 6.20 & 0.68 \\
\hline Decision Quality & 2.00 & 0.76 & 6.40 & 0.51 & 6.60 & 0.51 \\
\hline
\end{tabular}

Table 8: I used a seven-item questionnaire to measure committee members' perceptions of the current evaluation process. I administered the same questionnaire to the committee members after the first year and after the second year of implementation of CROSS. All the pre-CROSS means were significantly smaller than the firstyear means with the exception of simplicity. Statistical analysis of pre-CROSS and second-year ratings revealed similar results.

these characteristics. CROSS combines these subjective values numerically to provide an overall score for each project.

One reason to use CROSS is explicitness. In evaluating projects, DMs include a number of criteria. Furthermore, in applying these criteria, they consider the relative importance of the stakeholder departments, their probability of occurrence, and their intrinsic weights. Unless DMs consider these factors separately and explicitly, they risk neglecting some of the available information in making the final selections. CROSS focuses on problem decomposition to help DMs to analyze the problem and more accurately synthesize the results. This problem decomposition calls for structuring the problem in smaller and more manageable pieces. Decomposition encourages DMs to carefully consider the elements of uncertainty in different parts of the problem and to think about different objectives. CROSS decomposes the projectevaluation process into manageable steps and integrates the results from all the steps to arrive at an optimal solution.

Another reason for using CROSS is consistency. When judgments are expressed as separate numerical values, it is possible to assign a set of weights to the various criteria considered and then to apply these weights across all projects in the evaluation process.
In the absence of separate value judgments, it is difficult to apply a set of weights consistently among criteria when evaluating projects. CROSS provides a consistent combination of all assessments among all the projects. Whether the assessments faithfully represent real-world circumstances depends on the competence and degree of effort the DMs exert in making the assessments.

CROSS is simple because it has a scoring system that is easy to understand. In addition, it is flexible because it does not limit the number of projects or factors to be examined, and it promotes participation because the process of decomposition requires input from different levels of management. Furthermore, managers frequently complain that analytical procedures ignore subjective judgments. Such procedures often purport to generate optimal solutions on the basis of purely objective input. Subjective judgments are an important aspect of CROSS. CROSS not only allows for the inclusion of subjective judgments, it requires them.

The most important potential benefit of CROSS is its usefulness in examining how sensitive the projectsuccess factors are to changes in the portfolio of selected projects. CROSS also address questions about the sensitivity of the optimal budget allocation to changes in the relative importance of the stakeholders 


\begin{tabular}{|c|c|c|c|c|c|}
\hline \multirow{2}{*}{$\begin{array}{l}\text { Pair of } \\
\text { Alternatives }\end{array}$} & \multicolumn{5}{|c|}{ Criteria } \\
\hline & C1 & C2 & C3 & $\mathrm{C} 4$ & C5 \\
\hline$A_{1}-A_{2}$ & 42.6 & $N / F$ & $N / F$ & $\mathrm{~N} / \mathrm{F}$ & $\mathrm{N} / \mathrm{F}$ \\
\hline$A_{1}-A_{3}$ & $\mathrm{~N} / \mathrm{F}$ & N/F & $N / F$ & $\mathrm{~N} / \mathrm{F}$ & $\mathrm{N} / \mathrm{F}$ \\
\hline$A_{1}-A_{4}$ & 30.2 & 442.3 & $N / F$ & $\mathrm{~N} / \mathrm{F}$ & $\mathrm{N} / \mathrm{F}$ \\
\hline$A_{1}-A_{5}$ & $\mathrm{~N} / \mathrm{F}$ & N/F & $N / F$ & $\mathrm{~N} / \mathrm{F}$ & $N / F$ \\
\hline$A_{1}-A_{6}$ & 42.4 & $\mathrm{~N} / \mathrm{F}$ & $N / F$ & $\mathrm{~N} / \mathrm{F}$ & $\mathrm{N} / \mathrm{F}$ \\
\hline$A_{1}-A_{7}$ & 49.6 & $\mathrm{~N} / \mathrm{F}$ & $N / F$ & $\mathrm{~N} / \mathrm{F}$ & $\mathrm{N} / \mathrm{F}$ \\
\hline$A_{1}-A_{8}$ & $\mathrm{~N} / \mathrm{F}$ & $\mathrm{N} / \mathrm{F}$ & $N / F$ & $\mathrm{~N} / \mathrm{F}$ & $\mathrm{N} / \mathrm{F}$ \\
\hline$A_{1}-A_{9}$ & 31.5 & 387.5 & $N / F$ & $\mathrm{~N} / \mathrm{F}$ & $\mathrm{N} / \mathrm{F}$ \\
\hline$A_{1}-A_{10}$ & $\mathrm{~N} / \mathrm{F}$ & $\mathrm{N} / \mathrm{F}$ & $N / F$ & $\mathrm{~N} / \mathrm{F}$ & $\mathrm{N} / \mathrm{F}$ \\
\hline$A_{2}-A_{3}$ & 47.6 & $N / F$ & $N / F$ & $\mathrm{~N} / \mathrm{F}$ & $\mathrm{N} / \mathrm{F}$ \\
\hline$A_{2}-A_{4}$ & 48.4 & $\mathrm{~N} / \mathrm{F}$ & $N / F$ & $\mathrm{~N} / \mathrm{F}$ & $\mathrm{N} / \mathrm{F}$ \\
\hline$A_{2}-A_{5}$ & $\mathrm{~N} / \mathrm{F}$ & $N / F$ & $N / F$ & $N / F$ & $\mathrm{~N} / \mathrm{F}$ \\
\hline$A_{2}-A_{6}$ & $\mathrm{~N} / \mathrm{F}$ & N/F & $N / F$ & $\mathrm{~N} / \mathrm{F}$ & $\mathrm{N} / \mathrm{F}$ \\
\hline$A_{2}-A_{7}$ & 32.1 & 436.7 & $N / F$ & $\mathrm{~N} / \mathrm{F}$ & $\mathrm{N} / \mathrm{F}$ \\
\hline$A_{2}-A_{8}$ & 41.6 & N/F & $N / F$ & $\mathrm{~N} / \mathrm{F}$ & $\mathrm{N} / \mathrm{F}$ \\
\hline$A_{2}-A_{9}$ & 34.2 & 296.4 & $N / F$ & $N / F$ & $\mathrm{~N} / \mathrm{F}$ \\
\hline$A_{2}-A_{10}$ & $\mathrm{~N} / \mathrm{F}$ & N/F & $N / F$ & $\mathrm{~N} / \mathrm{F}$ & $\mathrm{N} / \mathrm{F}$ \\
\hline$A_{3}-A_{4}$ & $\mathrm{~N} / \mathrm{F}$ & $\mathrm{N} / \mathrm{F}$ & $N / F$ & $\mathrm{~N} / \mathrm{F}$ & $\mathrm{N} / \mathrm{F}$ \\
\hline$A_{3}-A_{5}$ & 32.5 & 468.9 & $N / F$ & $\mathrm{~N} / \mathrm{F}$ & $\mathrm{N} / \mathrm{F}$ \\
\hline$A_{3}-A_{6}$ & $\mathrm{~N} / \mathrm{F}$ & $\mathrm{N} / \mathrm{F}$ & $N / F$ & $\mathrm{~N} / \mathrm{F}$ & $\mathrm{N} / \mathrm{F}$ \\
\hline$A_{3}-A_{7}$ & 41.0 & $N / F$ & $N / F$ & $\mathrm{~N} / \mathrm{F}$ & $\mathrm{N} / \mathrm{F}$ \\
\hline$A_{3}-A_{8}$ & 33.7 & 356.2 & $\mathrm{~N} / \mathrm{F}$ & $\mathrm{N} / \mathrm{F}$ & $\mathrm{N} / \mathrm{F}$ \\
\hline$A_{3}-A_{9}$ & $\mathrm{~N} / \mathrm{F}$ & N/F & $N / F$ & $\mathrm{~N} / \mathrm{F}$ & $N / F$ \\
\hline$A_{3}-A_{10}$ & 43.5 & $\mathrm{~N} / \mathrm{F}$ & $N / F$ & $N / F$ & $\mathrm{~N} / \mathrm{F}$ \\
\hline$A_{4}-A_{5}$ & $\mathrm{~N} / \mathrm{F}$ & $\mathrm{N} / \mathrm{F}$ & $N / F$ & $\mathrm{~N} / \mathrm{F}$ & $\mathrm{N} / \mathrm{F}$ \\
\hline$A_{4}-A_{6}$ & 33.9 & 464.0 & $N / F$ & $N / F$ & $\mathrm{~N} / \mathrm{F}$ \\
\hline$A_{4}-A_{7}$ & $\mathrm{~N} / \mathrm{F}$ & N/F & $N / F$ & $\mathrm{~N} / \mathrm{F}$ & $N / F$ \\
\hline$A_{4}-A_{8}$ & $\mathrm{~N} / \mathrm{F}$ & $N / F$ & $N / F$ & $N / F$ & $\mathrm{~N} / \mathrm{F}$ \\
\hline$A_{4}-A_{9}$ & 44.6 & $\mathrm{~N} / \mathrm{F}$ & $N / F$ & $\mathrm{~N} / \mathrm{F}$ & $N / F$ \\
\hline$A_{4}-A_{10}$ & $\mathrm{~N} / \mathrm{F}$ & $\mathrm{N} / \mathrm{F}$ & $N / F$ & $\mathrm{~N} / \mathrm{F}$ & $\mathrm{N} / \mathrm{F}$ \\
\hline$A_{5}-A_{6}$ & $\mathrm{~N} / \mathrm{F}$ & $\mathrm{N} / \mathrm{F}$ & $N / F$ & $\mathrm{~N} / \mathrm{F}$ & $\mathrm{N} / \mathrm{F}$ \\
\hline$A_{5}-A_{7}$ & 50.6 & $\mathrm{~N} / \mathrm{F}$ & $N / F$ & $N / F$ & $\mathrm{~N} / \mathrm{F}$ \\
\hline$A_{5}-A_{8}$ & 41.2 & $\mathrm{~N} / \mathrm{F}$ & $\mathrm{N} / \mathrm{F}$ & $\mathrm{N} / \mathrm{F}$ & $\mathrm{N} / \mathrm{F}$ \\
\hline$A_{5}-A_{9}$ & $\mathrm{~N} / \mathrm{F}$ & $\mathrm{N} / \mathrm{F}$ & $N / F$ & $\mathrm{~N} / \mathrm{F}$ & $N / F$ \\
\hline$A_{5}-A_{10}$ & 31.6 & 324.7 & $\mathrm{~N} / \mathrm{F}$ & $\mathrm{N} / \mathrm{F}$ & $\mathrm{N} / \mathrm{F}$ \\
\hline$A_{6}-A_{7}$ & $\mathrm{~N} / \mathrm{F}$ & $\mathrm{N} / \mathrm{F}$ & $N / F$ & $\mathrm{~N} / \mathrm{F}$ & $\mathrm{N} / \mathrm{F}$ \\
\hline$A_{6}-A_{8}$ & $\mathrm{~N} / \mathrm{F}$ & $\mathrm{N} / \mathrm{F}$ & $\mathrm{N} / \mathrm{F}$ & $\mathrm{N} / \mathrm{F}$ & $\mathrm{N} / \mathrm{F}$ \\
\hline$A_{6}-A_{9}$ & 47.4 & $\mathrm{~N} / \mathrm{F}$ & $N / F$ & $\mathrm{~N} / \mathrm{F}$ & $\mathrm{N} / \mathrm{F}$ \\
\hline$A_{6}-A_{10}$ & $\mathrm{~N} / \mathrm{F}$ & $\mathrm{N} / \mathrm{F}$ & $N / F$ & $\mathrm{~N} / \mathrm{F}$ & $\mathrm{N} / \mathrm{F}$ \\
\hline$A_{7}-A_{8}$ & 34.7 & 295.4 & $N / F$ & $\mathrm{~N} / \mathrm{F}$ & $N / F$ \\
\hline$A_{7}-A_{9}$ & 42.4 & $\mathrm{~N} / \mathrm{F}$ & $\mathrm{N} / \mathrm{F}$ & $\mathrm{N} / \mathrm{F}$ & $\mathrm{N} / \mathrm{F}$ \\
\hline$A_{7}-A_{10}$ & $\mathrm{~N} / \mathrm{F}$ & $N / F$ & $N / F$ & $\mathrm{~N} / \mathrm{F}$ & $\mathrm{N} / \mathrm{F}$ \\
\hline$A_{8}-A_{9}$ & 46.6 & $\mathrm{~N} / \mathrm{F}$ & $N / F$ & $N / F$ & $\mathrm{~N} / \mathrm{F}$ \\
\hline$A_{8}-A_{10}$ & 51.6 & $N / F$ & $N / F$ & $\mathrm{~N} / \mathrm{F}$ & $\mathrm{N} / \mathrm{F}$ \\
\hline$A_{9}-A_{10}$ & $\mathrm{~N} / \mathrm{F}$ & $\mathrm{N} / \mathrm{F}$ & $\mathrm{N} / \mathrm{F}$ & $\mathrm{N} / \mathrm{F}$ & $\mathrm{N} / \mathrm{F}$ \\
\hline
\end{tabular}

Table 9: This table gives the $\delta_{k, i, j}^{\prime}$ values of different pairs of alternatives $\left(A_{1}, \ldots, A_{10}\right)$ and the safety criteria $\left(C_{1}, \ldots, C_{5}\right)$ for DM A. As shown, criteria $C_{3}, C_{4}$, and $C_{5}$ are robust criteria because all $\delta_{k, i, j}^{\prime}$ (for $1 \leq i \leq j \leq M$ and $1 \leq k \leq N$ ) values associated with them are nonfeasible (N/F). A nonfeasible value is derived if there is no $\delta_{k, i, j}^{\prime}$ value such that the rankings are reversed. and the criteria and of the project-success factors to changes in probabilities of occurrence.

Finally, using a step-by-step and structured approach like CROSS does not imply a deterministic approach to project evaluation. While CROSS enables DMs to crystallize their thoughts and organize their beliefs, it should be used very carefully. The effectiveness of the model depends heavily on the DMs' abilities to make sound judgments. CROSS relies on intuitive methods, such as subjective estimation of probabilities and weights. While a DM's judgments often mirror the DM's belief in the importance of certain events, they should be used with caution. As with any decision-analysis model, the researchers and practicing managers must be aware of the limitations of subjective estimates.

\section{Acknowledgments}

This research was supported by NASA grants NGT-52605 and NGT-60002. I am grateful to Prafulla Joglekar, Dennis Kennedy, Jack Rappaport, the editor-in-chief, the associate editor, two anonymous reviewers, and Mary Haight for their insightful comments and suggestions.

\section{References}

Aczel, J., T. L. Saaty. 1983. Procedures for synthesizing ratio judgments. J. Math. Psych. 27(1) 93-102.

Beck, M. P., B. W. Lin. 1983. Some heuristics for the consensus ranking problem. Comput. Oper. Res. 10(1) 1-7.

Brun, W., K. H. Teigen. 1988. Verbal probabilities: Ambiguous, context-dependent, or both? Organ. Behavior Human Decision Processes 41(3) 390-404.

Budescu, D. V., T. S. Wallsten. 1985. Consistency in interpretation of probabilistic phrases. Organ. Behavior Human Decision Processes 36(3) 391-405.

Coffin, M. A., B. W. Taylor III. 1996. Multiple criteria R\&D project selection and scheduling using fuzzy logic. Comput. Oper. Res. 23(3) 207-220.

Dyer, J. S. 1990a. Remarks on the analytic hierarchy process. Management Sci. 36(3) 249-258.

- 1990b. A clarification of "Remarks on the analytic hierarchy process." Management Sci. 36(3) 274-275.

Dyer, R. F., E. H. Forman. 1992. Group decision support with the analytic hierarchy process. Decision Support Systems 8(2) 99-124.

Expert Choice. Computer Software. Decision Support Software, Inc., McLean, VA.

Fahrni, P. 1990. An application-oriented guide to R\&D project selection and evaluation methods. R\&D Management 20(2) 155-171.

Graves, S. B., J. L. Ringuest. 1991. Evaluating competing R\&D investments. Res. Tech. Management 34(4) 32-36. 
Harker, P. T., L. G. Vargas. 1987. The theory of ratio scale estimation: Saaty's analytic hierarchy process. Management Sci. 33(11) 1383-1403.

. 1990. Reply to "Remarks on the analytic hierarchy process" by J. S. Dyer. Management Sci. 36(3) 269-273.

Hazelrigg, G. A., Jr., F. L. Huband. 1985. RADSIM-A methodology for large-scale R\&D program assessment. IEEE Trans. Engrg. Management 32(3) 106-116.

Keeney, R. L., H. Raiffa. 1976. Decisions with Multiple Objectives: Preference and Value Tradeoffs. John Wiley and Sons, New York.

Koriat, A., S. Lichtenstein, B. Fischoff. 1980. Reasons for confidence. J. Experiment. Psych. 6(1) 107-118.

Lewis, H. S., T. W. Butler. 1993. An interactive framework for multiperson, multiobjective decisions. Decision Sci. 24(1) 1-22.

Liberatore, M. J. 1987. An extension of the analytic hierarchy process for industrial R\&D project selection and resource allocation. IEEE Trans. Engrg. Management 38(3) 12-18.

Lockett, G., B. Hetherington, P. Yallup. 1984. Modeling a research portfolio using AHP: A group decision process. RED Management 16(2) 151-160.

Lootsma, F. A., T. C. A. Mensch, F. A. Vos. 1990. Multi-criteria analysis and budget reallocation in long-term research planning. Eur. J. Oper. Res. 47(3) 293-305.

Mandakovic, T., W. E. Souder. 1985. An interactive decomposable heuristic for project selection. Management Sci. 31(10) 1257-1271.

Mathieu, R. G., J. E. Gibson. 1993. A methodology for large-scale R\&D planning based on cluster analysis. IEEE Trans. Engrg. Management 40(3) 283-292.

Mehrez, A. 1988. Selecting R\&D projects: A case study of the expected utility approach. Technovation 8(4) 299-311.

Melachrinoudis, E., K. Rice. 1991. The prioritization of technologies in a research laboratory. IEEE Trans. Engrg. Management 38(3) 269-278.

Merkhofer, M. W. 1987. Quantifying judgmental uncertainty: Methodology, experiences, and insights. IEEE Trans. Systems, Man, Cybernetics 5(5) 741-752.

Moore, J. R., N. R. Baker. 1969. An analytical approach to scoring model design-Application to research and development project selection. IEEE Trans. Engrg. Management 16(3) 90-98.

Muralidhar, K., R. Santhanam, R. L. Wilson. 1990. Using analytic hierarchy process for information system project selection. Inform. Management 18(2) 87-95.

Saaty, T. L. 1972. An eigenvalue allocation model for prioritization and planning. Working paper, Energy Management and Policy Center, University of Pennsylvania, Philadelphia, PA.

- 1977a. A scaling method for priorities in hierarchical structures. J. Math. Psych. 15(3) 234-281.

- 1977b. Modeling unstructured decision problems: A theory of analytical hierarchies. Proc. First Internat. Conf. Math. Modeling. St. Louis, MO, 69-77.

—. 1980. The Analytic Hierarchy Process. McGraw-Hill, New York.

_. 1990a. Multicriteria Decision Making: The Analytic Hierarchy Process. RWS Publications, Pittsburgh, PA. 1990b. An exposition of the AHP in reply to the paper "Remarks on the analytic hierarchy process." Management Sci. 36(3) 259-268.

Santhanam, R., J. Kyparisis. 1995. A multiple criteria decision model for information system project selection. Comput. Oper. Res. 22(8) 807-818.

—, K. Muralidhar, M. Schniederjans. 1989. A zero-one goal programming approach for information system project selection. Omega 17(6) 583-593.

Schniederjans, M., R. Santhanam. 1993. A multi-objective constrained resource information system project selection problem. Eur. J. Oper. Res. 70(2) 244-253.

Schoemaker, P. J. H. 1993. Multiple scenario development: Its conceptual and behavioral foundation. Strategic Management J. 14(3) 193-213.

_ J. E. Russo. 1993. A pyramid of decision approaches. California Management Rev. 36(1) 9-31.

— C. C. Waid. 1978. A comparison of several methods for constructing additive representations of multi-attribute preferences. Working paper, Wharton Applied Research Center, University of Pennsylvania, Philadelphia, PA.

Shim, J. P. 1989. Bibliographical research on the analytic hierarchy process (AHP). Socio-Econom. Planning Sci. 23(3) 161-167.

Spetzler, C. S., C.-A. S. Stael von Holstein. 1975. Probability encoding in decision analysis. Management Sci. 22(3) 340-358.

Steeb, R., S. Johnson. 1981. A computer based interactive system for group decision making. IEEE Trans. Systems, Man Cybernetics 11(8) 544-552.

Stover, J. G., T. J. Gordon. 1978. Cross-impact analysis. J. Fowles, ed. Handbook of Futures Research. Greenwood Publications, Westport, CT.

Tavana, M., D. Kennedy, B. Mohebbi. 1997. An applied study using the analytic hierarchy process to translate common verbal phrases to numerical probabilities. J. Behavioral Decision Making 10(2) 133-150.

Taylor, B. W., III, L. J. Moore, E. R. Clayton. 1982. R\&D project selection and manpower allocation with nonlinear goal programming. Management Sci. 28(10) 1149-1158.

Thomas, H. 1985. Decision analysis and strategic management of research and development. RED Management 15(1) 3-22.

Triantaphyllou, E., A. Sanchez. 1997. A sensitivity analysis approach for some deterministic multi-criteria decisionmaking methods. Decision Sci. 28(1) 151-194.

Vepsalainen, A. P. J., G. L. Lauro. 1988. Analysis of R\&D portfolio strategies for contract competition. IEEE Trans. Engrg. Management 35(3) 181-186.

Vickers, B. 1992. Using GDSS to examine the future European automobile industry. Futures 24(8) 789-812.

Weber, R., B. Werners, H. J. Zimmerman. 1990. Planning models for research and development. Eur. J. Oper. Res. 48(2) 175-188.

Weigelt, K., I. Macmillan. 1988. An integrative strategic analysis framework. Strategic Management J. 9(special issue) 27-40.

Weiss, E. N., V. R. Rao. 1987. AHP design issues for large-scale systems. Decision Sci. 18(1) 43-61. 
Zahedi, F. 1986. The analytical hierarchy process-A survey of the method and its applications. Interfaces 16(4) 96-108.

Zeleny, M. 1982. Multiple Criteria Decision Making. McGraw Hill, New York.

J. T. Mullin, Chief, Shuttle Project Engineering, National Aeronautics and Space Administration, John F. Kennedy Space Center, Kennedy Space Center, Florida 32899, writes: "The purpose of this letter is to share the implementation and results of the research project you completed during the last two summers as a NASA/ASEE Summer Faculty Fellow at the Kennedy Space Center. We appreciate your relentless hard work, given the difficulty of the evaluation and prioritization of Engineering Support Requests (ESRs).

"The Consensus-Ranking Organizational-Support System (CROSS), a multicriteria decision-support system that you developed, was tested last year by executing a prototype model. The model captured the complexities of various organizational interests and analyzed the information with a structured process. We, in Shuttle Project Engineering, became familiar with various components of the model which consisted of the Analytic Hierarchy Process (AHP), the entropy concept, and the Maximize-Agreement Heuristic (MAH). We also developed an understanding of the effect of subjective probabilities within the system.

"After reviewing the results of the prototype model, we incorporated, with your assistance, a few refinements and implemented the CROSS successfully. All of the organizations and their representatives that have actively participated in the CROSS development are enthused about its practicability and the benefits derived from its use. The benefits certainly exceeded our expectations in satisfying different objectives through its structured evaluation and prioritization of ESRs.

"The adaptability of CROSS will enable us to apply its conceptuality to other established processes at $\mathrm{KSC}$, as well as provide additional flexibilities in making necessary changes in the future.

"Again, we thank you for this valuable new tool, CROSS, that you have developed for us. It has been an enlightening and very productive experience to have you in the Shuttle Project Engineering Office at NASA." 